\title{
Spinal dysraphisms: highlighting discrepancies in the current literature and emphasizing on the need for a consensus
}

\author{
Ankit Balani ${ }^{1}$, Chinky Chatur ${ }^{1}$, Asthik Biswas ${ }^{2}$, Ozgur Oztekin $^{3}$, Kshitij Mankad $^{1}$ \\ ${ }^{1}$ Great Ormond Street Hospital for Children NHS Foundation Trust, London, UK; ${ }^{2}$ The Hospital for Sick Children, Toronto, Canada; ${ }^{3}$ Health \\ Science University, Izmir, Turkey
}

Correspondence to: Dr. Kshitij Mankad. Great Ormond Street Hospital for Children NHS Foundation Trust, London, UK. Email: rmankad@gmail.com.

Provenance and Peer Review: This article was commissioned by the editorial office, Quantitative Imaging in Medicine and Surgery. This article did not undergo external peer review.

Submitted Jan 19, 2020. Accepted for publication Feb 03, 2020.

doi: 10.21037/qims.2020.02.04

View this article at: http://dx.doi.org/10.21037/qims.2020.02.04

Congenital anomalies of the spine and spinal cord have an estimated incidence of 1-3/1,000 live births; however, there has been a significant decline in the past few decades primarily due to maternal folic acid supplementation accompanied by better maternal nutrition, improved antenatal care, availability of prenatal ultrasound and biochemical marker screening (1). Owing to the advancements in diagnostic imaging and surgical techniques, the literature on congenital anomalies of spine and spinal cord has been on a steady rise, however, the presence of numerous discrepancies in the published literature has added to the ambiguity that is associated with the entity. The purpose of this editorial is to highlight the existing discrepancies in the published literature and to highlight the urgent need for developing a consensus in terms of nomenclatures and classification of spinal anomalies.

Congenital malformations of spine and spinal cord are loosely referred to as 'spinal dysraphisms' which as a term is a misnomer in itself. The term is indicative of defect in closure of neural tube and therefore strictly represents only open defects due to defective neurulation (2). The basis of the word 'dysraphism' is 'raphe' which in biology strictly is 'a groove, ridge or seam in an organ or tissue, typically marking the line where two halves fused in the embryo'. Hence the term, spinal dysraphisms, implies only to midline fusion defects and is mistakenly considered to be synonymous to congenital malformations of spine and spinal cord.

Literature on embryogenesis of spine and spinal cord has been ever increasing; however, most of the studies are based on chick embryos with secondary implications on human embryos and thus may partially account for the prevalent discrepancies. The literature based on human embryos is quite limited. Most of the classification systems of spinal dysraphisms are based on embryogenesis with different authors proposing different classifications.

Caudal regression syndrome (CRS) is a complex dysraphic anomaly characterized by total or partial agenesis of the spinal column associated with variable genital anomalies, gastrointestinal anomalies including anal imperforation, renal dysplasia/aplasia, pulmonary hypoplasia, and lower limb abnormalities. The term CRS etymologically implies excessive regression of the embryonic tail that cannot be adequately applied to tail-less animals including humans, and thus is relatively inappropriate and could be replaced by "caudal dysgenesis syndrome" (2). Varying classification systems have placed CRS into different classification subsets. Whilst some authors believe it to be an anomaly of gastrulation $(3,4)$ others believe it to be an anomaly of secondary neurulation (5). Traditionally, CRS has been categorized into two subsets depending on the location and shape of the conus medullaris, either high and abrupt (type I) or low and tethered (type II). Type I CRS occurs due to anomalous development of the tail bud and part of true notochord (interference of both primary and secondary neurulation) resulting into vertebral aplasia ranging from absence of coccyx and lower mid-sacrum to aplasia of all coccygeal, sacral, lumbar and lower thoracic 
vertebrae and club or wedge shaped abrupt termination of spinal cord. Type II CRS, on the other hand, is believed to be due to anomalous development of part or whole of the tail bud with unaffected notochord (interference of secondary neurulation only) which is characterized by less severe vertebral dysgenesis than in type I and conus being stretched caudally and tethered to tight filum, lipoma, terminal myelocystocele, lipomyelomeningocele, or teratomas (6). Therefore, it may be worthwhile to sub classify these two subsets of CRS as different entities with different embryological bases.

The other area of discrepancy is concerning the nomenclature and embryogenesis of spinal lipomas. Some authors classify them as lipomas with dural defect (lipomyelocele and lipomyelomeningocele) and intradural lipomas without dural defect which are considered to be anomalies of primary neurulation $(2,4,6)$. Some authors consider the term 'lipomyelomeningocele' to be a misnomer because it actually suggests herniation of neural elements through a spina bifida defect into the meningeal sac, whilst, in fact, the lipomatous tissue inserts into the conus, and it is fat and not the neural tissue that herniates through the dorsal bony defect to attach to the subcutaneous mass (7). Others have however classified spinal lipomas into different subtypes depending on embryology and have preferred using the term spinal lipomas with or without extra-spinal extension instead of lipomyelocele and lipomyelomeningocele respectively $(8,9)$ Varying classification systems have been published for spinal lipomas, of which recent ones are by Pang et al. (8) and by Morota et al. (9).

Pang et al. classified spinal lipomas as: (I) dorsal type: lipoma-cord interface being entirely on the surface of cord sparing the distal conus with neat definition of a junctional line; (II) transitional lipoma: similar to dorsal type there is discrete fusion line however the lipoma may plunge caudal to the conus medullaris; (III) chaotic lipoma: caudal portion of lipoma is ventral to neural placode, does engulf neural tissue and nerve roots with blurring of fusion line distally; (IV) terminal lipomas: lipomas insert into caudal extremity of conus without blending with the spinal cord or its root entry zones and the dural sac/dural myofascial coverings are intact $(8,10)$.

Morota $e t$ al. proposed a new classification of spinal lipomas based on their embryonic stage: (I) type 1: due to primary neurulation failure only, wherein the lipomacord interface occurs on the dorsal surface of cord with pathological spina bifida and the conus medullaris being distal or ventral in relation to caudal end of lipoma (encompassing the dorsal and transitional lipomas by Pang et al.), (II) type 2: due to failed neurulation between the primary and secondary stages where in in addition to lipoma and pathological spina bifida, the conus medullaris is malformed and difficult to recognize on MRI (similar to chaotic lipoma by Pang et al.), (III) type 3: due to early phase secondary neurulation failure wherein the caudal end of conus medullaris is unformed, directly connects to the lipoma which in turn extends in the caudal direction, penetrating the caudal end of dura to connect to subcutaneous fat through the sacral hiatus (no pathological spina bifida/dural defect due to lipoma); (IV) type 4: due to late phase secondary neurulation failure wherein lipoma is located in filum terminale and caudal end of conus medullaris is normal. The type 3 and 4 lipomas according to the new classification are similar to the terminal lipomas by Pang et al. (8). The authors highlight the concept of junctional neurulation which has not been discussed much before.

In our experience, we have encountered more than a few cases where we faced difficulty in classifying lipomas on the basis of the current classification systems at our disposal. In some cases, different paediatric neuroradiologists could not come to a consensus regarding the type of spinal lipoma. Here we wish to draw attention to a few of such cases. Our first case was a 9-week-old boy with cloacal exstrophy who underwent magnetic resonance imaging (MRI) of the spine as a part of routine imaging protocol. MRI showed a spinal lipoma on the dorsal surface of the cord sparing the distal conus medullaris, showing sharp line of demarcation, however, there was no obvious dural defect due to the lipoma, thereby it did not fit exactly in the existing classification systems. There was lack of the pathological dural defect at the level of lipoma for it to be Type 1 lipoma according to Morota et al./Pang et al. dorsal type of lipoma. The well-formed caudal end of the conus medullaris and the location of lipoma in relation to cord rules out the possibility of Type 3 lipoma according to Morota et al./Pang et al. terminal type of lipoma (Figure 1). However, irrespective of the classification type, from a clinical point of view, the patient had cloacal exstrophy and thus was likely to have a worse urological outcome otherwise. If there is a need for surgical resection, it would be relatively easier to resect this lipoma due to its sharp line of demarcation with the neural placode. Our second example case was an 18 month old girl with skin covered lump in the back undergoing MRI of spine for detailed evaluation which showed dural defect with spinal lipoma 

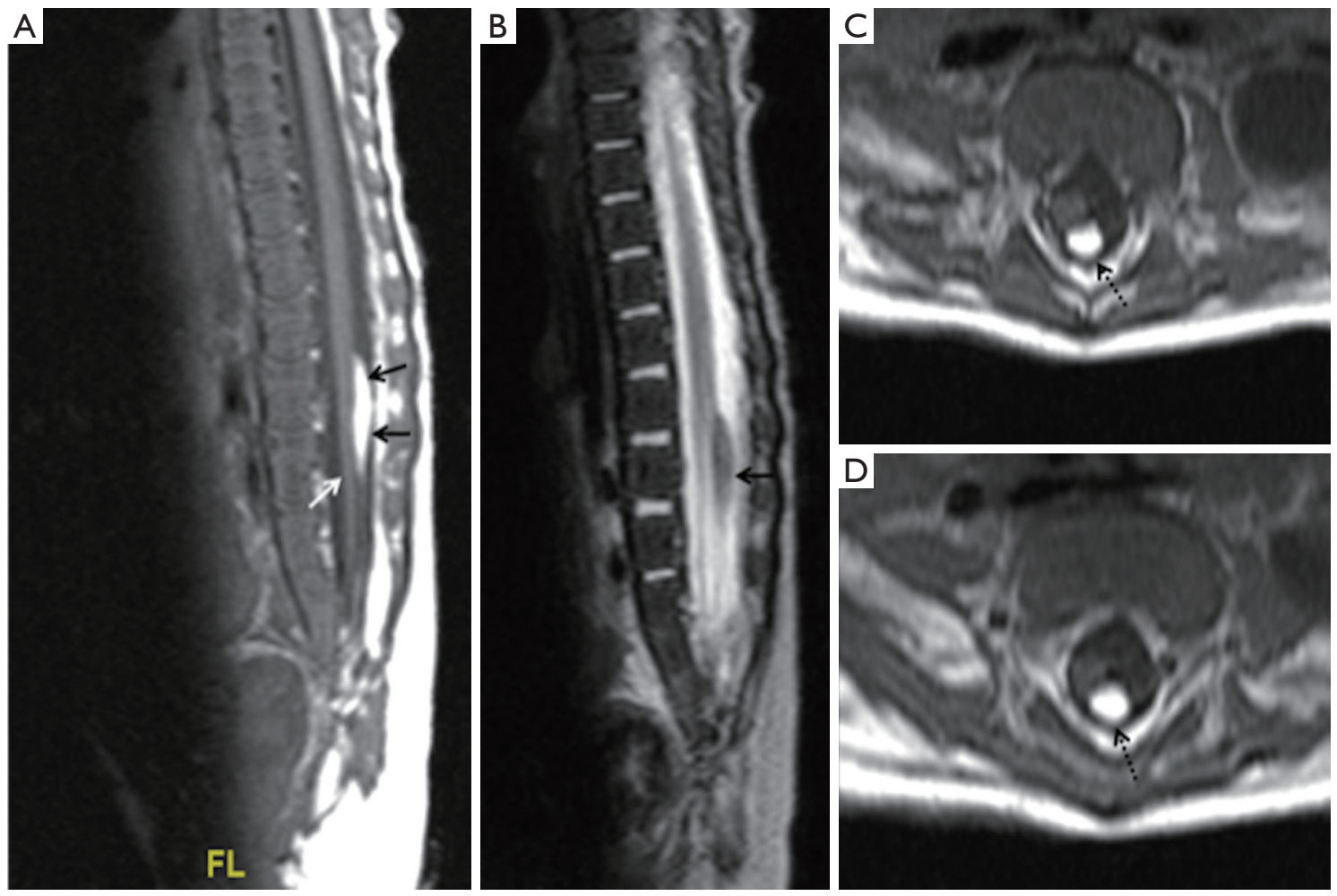

Figure 1 Nine-week old boy with cloacal exstrophy. MRI of spine in T1 sagittal (A), T2 sagittal (B), T1 axials (C,D) showing spinal lipoma (black arrows) on the dorsal surface of cord sparing the distal conus medullaris (white arrow), showing sharp line of demarcation, however, there was no obvious dural defect due to the lipoma (dashed black arrow), thereby this case did not fit exactly in the existing classification systems. There was lack of the pathological dural defect at the level of lipoma for it to be Type 1 lipoma according to Morota et al./Pang et al. dorsal type of lipoma. The well-formed caudal end of conus medullaris and the location of lipoma in relation to cord ruled out the possibility of Type 3 lipoma according to Morota et al./Pang et al. terminal type of lipoma.

(pathological spina bifida) with a discrete fusion line at the lipoma-cord interface on sagittal imaging and lipoma seen caudal to the conus medullaris suggesting possible Pang et al. transitional type lipoma/type 1 lipoma according to Morota et al. However, there appears to be a blurred interface with conus medullaris on axial imaging with the caudal portion of lipoma extending ventral to the neural placode pointing towards possible Pang et al. Chaotic type lipoma/type 2 lipoma according to Morota et al. (Figure 2). Thus, in our experience, there is difficulty in differentiating the transitional (type 1) lipomas from chaotic (type 2) lipomas which from a surgical and clinical point of view is very important.

Further, there has been incongruity in the nomenclature of non-terminal myelocystocele as well. Some authors sub classify them into complete and abortive forms $(2,11)$ while others have classified them under the umbrella term of limited dorsal myeloschisis (LDM) (12). LDM is a distinctive entity with characteristic external and internal features. It has been classified as non-saccular and saccular types with saccular type further sub classified into basal nodule, stalk to dome and non-terminal myelocystocele (12).

It is possible that many LDM's may have been misreported as dermal sinus tracts (12). Also, there is a discrepancy regarding the true existence of "meningocele" which may represent saccular LDM with internal fibroneural bands and have been described using different terminologies including myelomeningocele manqué, dermal sinus tract and dermoid cysts (12). Thus, it may be worthwhile to consider dermal sinus tract and limited dorsal myeloschisis as a continuum rather than distinct entities.

Thus, by drawing attention to the existing discrepancies related to spinal dysraphisms, we wish to emphasize on the consequential need for a consensus on the embryogenesis and nomenclature of spinal dysraphisms by a team of expert neuroradiologists, neurosurgeons and embryologists. 

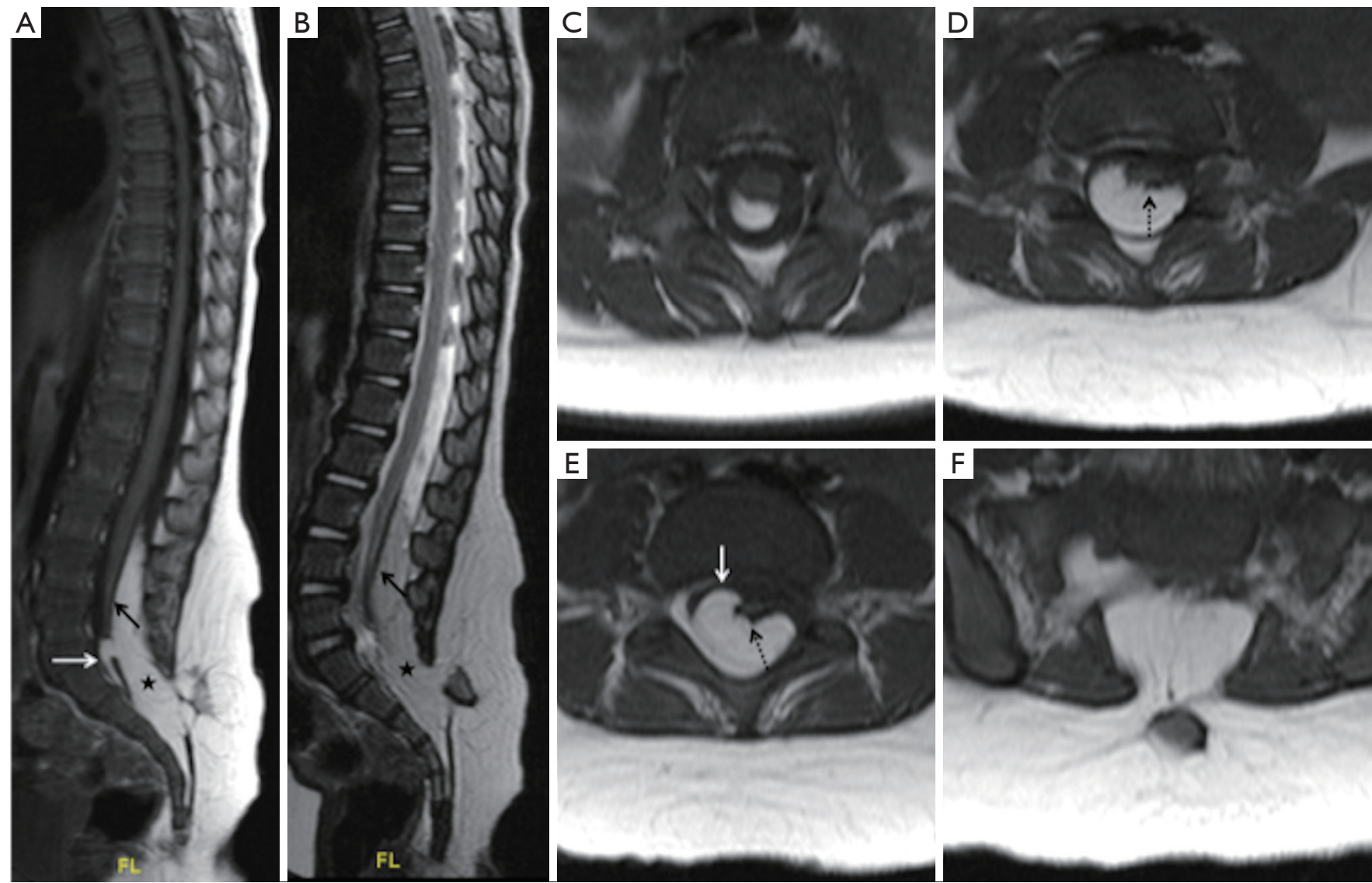

Figure 2 Eighteen-month old girl with skin covered lump in the back with MRI of spine in T1 sagittal (A), T2 sagittal (B), T1 axials (C,D,E,F) showing a dural defect with spinal lipoma (pathological spina bifida) (black asterisk) with a discrete fusion line at the lipoma-cord interface on sagittal imaging (black arrows) and lipoma seen caudal to the conus medullaris suggesting possible Pang et al. transitional type lipoma/ type 1 lipoma according to Morota et al. However, there appears to be a blurred interface with conus medullaris on axial imaging (D,E) (dashed black arrow) with the caudal portion of lipoma extending ventral to the neural placode (A,E) (white arrow) pointing towards possible Pang et al. Chaotic type lipoma/type 2 lipoma according to Morota et al.

\section{Acknowledgments}

Funding: None.

\section{Footnote}

Conflicts of Interest: KM serves as an unpaid Associate Editor of Quantitative Imaging in Medicine and Surgery. The other authors have no conflicts of interest to declare.

Open Access Statement: This is an Open Access article distributed in accordance with the Creative Commons Attribution-NonCommercial-NoDerivs 4.0 International License (CC BY-NC-ND 4.0), which permits the non- commercial replication and distribution of the article with the strict proviso that no changes or edits are made and the original work is properly cited (including links to both the formal publication through the relevant DOI and the license). See: https://creativecommons.org/licenses/by-nc-nd/4.0/.

\section{References}

1. Venkataramana NK. Spinal dysraphism. J Pediatr Neurosci 2011;6:S31-40.

2. Rossi A. Imaging in Spine and Spinal Cord Developmental Malformations: The ESNR Textbook. 2019:1-32.

3. Acharya UV, Pendharkar H, Varma DR, Pruthi N, Varadarajan S. Spinal dysraphism illustrated; Embroyology 
revisited. Indian J Radiol Imaging 2017;27:417-26.

4. Tortori-Donati P, Rossi A, Cama A. Spinal dysraphism: a review of neuroradiological features with embryological correlations and proposal for a new classification. Neuroradiology 2000;42:471-91.

5. Thompson D. Spinal dysraphic anomalies; classification, presentation and management. Paediatrics and Child Health 2010;24:397-403.

6. Rossi A, Cama A, Piatelli G, Ravegnani M, Biancheri $\mathrm{R}$, Tortori-Donati P. Spinal dysraphism: MR imaging rationale. J Neuroradiol 2004;31:3-24.

7. Dewan MC, Wellons JC. 7 - Spinal Dysraphism and Tethered Spinal Cord. In: Ellenbogen RG, Sekhar LN, Kitchen ND, et al. editors. Principles of Neurological Surgery (Fourth Edition). Philadelphia: 2018;116-32.e2.

8. Pang D, Zovickian J, Oviedo A. Long-term outcome of

Cite this article as: Balani A, Chatur C, Biswas A, Oztekin O, Mankad K. Spinal dysraphisms: highlighting discrepancies in the current literature and emphasizing on the need for a consensus. Quant Imaging Med Surg 2020;10(3):549-553. doi: 10.21037/qims.2020.02.04 total and near-total resection of spinal cord lipomas and radical reconstruction of the neural placode: part I-surgical technique. Neurosurgery 2009;65:511-28; discussion 528-9.

9. Morota N, Ihara S, Ogiwara H. New classification of spinal lipomas based on embryonic stage. 2017;19:428.

10. Pang D. Surgical management of complex spinal cord lipomas: how, why, and when to operate. A review. J Neurosurg Pediatr 2019;23:537-56.

11. Rossi A, Piatelli G, Gandolfo C, Pavanello M, Hoffmann C, Van Goethem JW, Cama A, Tortori-Donati P. Spectrum of nonterminal myelocystoceles. Neurosurgery 2006;58:50915; discussion 509-15.

12. Pang D, Zovickian J, Wong ST, Hou YJ, Moes GS. Limited dorsal myeloschisis: a not-so-rare form of primary neurulation defect. Childs Nerv Syst 2013;29:1459-84. 